\title{
DAMNOS POR OPERAÇÕES DE GUERRA
}

Esta materia não pode ser bem comprehendida, si não houver um estudo da evolução por que tem passado a idea do direito do Estado sobre a propriedade dos cidadãos. Antigamente, era geralmente acceita a doutrina do dominio do soberano sobre toda a propriedade dos seus subditos. A' medida que se enfraqueceu essa doutrina, e que o chamado dominio eminente foi sendo posto em duvida, augmentou-se o respeito pela propriedade particular, e nasceu o instituto da desapropriação, que é de data recente, posterior á revolução franceza, que proclama o respeito á propriedade. A desapropriação fundada na necessidade de se limitar a propriedade, é protectora desta. Depois da revolução francesa consagrou-se a propriedade como sendo um direito garantido pela lei constitucional. Essa promessa porém foi sempre limitada pelos poderes de policia, e assim, ainda mesmo na sua obra Direito das Cousas, Lafayette, firma o principio de estar sujeito quanto pertence aos particulares a ser limitado em seu uso pelas obrigações dos poderes municipaes, sem ficar por tal obrigado o poder publico a uma indemnização. Em tractando dos actos pelos quaes é destruida ou damnificada pelo Estado a propriedade particular, diz Lafayette que a doutrina vigente, quando escreveu o seu tratado de Direito Internacional, isto é, em 1902, era a de não ser o Estado obrigado a resarcir os damnos soffridos pelos particulares, si causados pela necessidade de pacificar tumultos e domar revoluçöes ou guer- 
ras civis, mas ajunta que desejavel seria que o fosse (I/376). Parece-me porém que a questão não pode ser collocada neste pé. Não se tracta de responsabilidade por acto illicito. Sabido é que não ha responsabilidade sem culpa. Os casos apresentados como excepções só apparentemente como taes são recebidos. Um delles é o da inversão dà presumpção dà culpa, preceituando a lei que as estradas de ferro, por exemplo, sejam obrigadas a provar não terem tido culpa no desastre occorrido. Tambem foi sustentado que ao patrão era que deveria incumbir a prova de não ter sido o desastre occorrido por culpa delle, mas sim por caso fortuito ou por culpa do empregado. O 2. ${ }^{\circ}$ caso é o que foi explicado pela supposta responsabilidadie objectiva. Mas hoje explica-se como sendo um risco de negocio, e no risco de negocio assenta o instituto da compensação dos accidentes no trabalho. Assim pois não se deve falar em responsabilidade do Estado pelos damnos que determinar em lucta civil ou externa, como sendo regida pelos principios que reguİa a indemnização por actos illicitos. Ao caso melhor é applicar o principio da desapropriação, segundo o qual é lid̦ito ao Estado, em dadas hypotheses, dispor da propriedade particular por necessidade ou utilidade publica. Indifferente é que o Estado peça a propriedadé immovel pelo proceso de desapropriação mais ou menos moroso que temos, ou que requisite bens moveis ou immoveis no momento de uma guerra ou de uma commoção intestina. O nosso Codigo Civil ligou os dois casos nos arts. 590 e 591. Pela sua amplitude, é bem claro que o art. 591 abrange não só o emprego da propriedade movel mas tambem o da immove!. Diz o art. 591 que, em casos de commoção intestina ou de guerra, poderão as autoridades usar da propriedade particular até onde o bem publico o exija. Si é licito á autoridade militar cortar forragem para seus animaes, tomar alimentos para as forças, apoderar-se 
de munições pertencentes a particulares, por que motivo não lhe será facultado tomar um immovel afim de dis. por delle seja para abrigo, seja para forte, seja para destruil-o ao intento de conseguir uma pontaria destinada a desalojar ou destruir o inimigo? Diz Clovis, ao commentar este artigo, que a hypothese não é de desapropria. ção, a quial extingue o direito de propriedade, mas é de uso da propriedade, salvo o caso de ser a recquisição de coisas consumiveis. Ora ahi está ao menos um caso em que é manifesta a passagem dia propriedade do dominio do particular para o Estado. Ainda pois que não haja sinão uso da propriedade particular, ainda quando a substancia da coisa seja conservada, ainda quando só haja uma detoriação pelo uso normal da coisa, á especie devem ser applicados os principios da desapropriação. Julgo pois que o art. 591 rege precisamente o caso de tomada de propriedade immovel para della usar ou para a destruir, o uso, e o abuso no sentido juridico technico deste ultimo vocabulo. Entendo pois que o Estado deve pagar como tendo sido desapropriado todo immovel ou todo movel que houver requisitado solemnemente ou que tenha tomado sem requisição por força da necessidade publica, e julgo que o art. 591 veio acudir ao desiderato de Lafayette. Desapropriação no sentido technico e restricto só se applica a immoveis, como se vê nos arts. 590 e 591 do Codigo Civil. Isto porém não impede que sejam seus principios extendidos as requisições e aos damnos sobre moveis.

Tem a maior importancia no gaso o preceito da lei interna. E' assim que Oppenheim, ao estudar o assumpto da responsabilidade do Estado pelos damnos á propriedade particular consequentes ás guerras civis ou externas, lembra que a França paga todos, quer tenham sido occasionados por ella, quer pelo inimigo interno ou externo. 
Abaixo se verá a que titulo tem ella feito taes pagamentos. Tambem importancia capital têm os tratados. E' esse mesmo Oppenheim que lembra que diversas republicas sul americanas, em que são frequentes as revoluções e tumultos, têm convencionado em seus tratados relativos á immigração que não respondem pelos damnos resultantes dessas perturbações da ordem publica, hypothese em que desapparece qualquer duvida, porque o contracto faz lei entre as partes.

Fóra porém a legislação interna brasileira, que é do maior interesse para nós, ha a considerar as leis da guerra estabelecidas pelo Instituto de Direito Internacional de Oxford em 9 de Outubro de 1880. Dizem essas regras, nos arts. 54 e segs., que a propriedade particular deve ser respeitada, e que, quando tomados meios de transporte (barcos, carros, etc) telegraphos, fabricas, cumpre que sejam restituidos após a terminação da lucta no Estado em que foram recebidos, e, si impossivel, com indemnização do estrago soffrido. Resta ver o espirito que anima o Direito Internacional moderno a este proposito. Oppenheim occupa-se com os actos dos revoltosos e com a responsabilidade do Estado pelos actos de seus prepostos. Firma em opposição que a regra de outrora era a de que os belligerantes podiam se apropriar dos bens publicos e privados no inimigo, mas que tal regra hoje obsoleta, foi substituida pela acceita no Regulamento de Haya, art. 46 onde se firmou que a propriedade particular não pode ser confiscada. Licito é ajuntar que este artigo fala duas vezes no respeito á propriedade particular, e que a colloca ao lado de direito de vida. Quanto á propriedade do inimigo, acceitando a tradiccional classificação, fala Oppeheim em immovel e movel. A immovel pode ser tomada unicamente para servir de hospitaes, alojamento sem indemnização por parte do occupante. Os moveis podem ser requisita- 
dos, mas com compensação após a celebração da paz. Antigamente pelo principio de que a guerra deve sustentar a guerra, assim como no processo o vencido paga as despezas, assim tambem era o vencido quem solvia o despendido na lucta cruenta. Tornando-se porém mais difficil o sustento do exercito fóra do paiz, começou a dar-se um abrandamento de tal principio no correr do seculo 17.

Oppenheim e os demais escriptores distinguem a requisição da destruição dos bens dos inimgos por neces. sidade, pois que a por simples desejo de fazer mal ao inimigo é prohibida pelo art. 23 do Reg. de Haya. Dizem que só a requisição dá logar a uma indemnização. Essa distincção é que, comquanto geralmente acceita, não me parece justa. Davis vae mesmo até quasi confessar a injustiça dessa maneira de tractar a materia. Referindo-se á occupação da propriedade inimiga, diz Da. vis que não consagra o Direito Internacional á obrigação de a indemnizar, e ajunta que só por politica e não por principio de justiça rigorosa deve ser paga a propriedade do inimigo. Mas o que é digno de menção é que affirma que illiberal e injusta como é esta practica, foi entretanto acceita universalmente por todos os tratadistas de Direito Internacional, e recebeu delles sanç̧ão embora muito a contragosto (pag. 307). Em se tratando de propriedade do subdito ou de extrangeiro residente, que é equiparado ao subdito, o Direito Internacional reporta-se ás leis locaes, ponto importantissimo, seja dito de passo é esta equiparação do nacional ao extrangeiro. Todavia distingue elle entre a propriedade tomada ou requisitada para uso publico e a que é destruida pelo bombardeamento ou por outras operações de guerra: ha indemnização no $1 .^{\circ}$ caso, mas não no $2 .^{\circ}$ Esta distincção é, a meu ver, absolutamente destituida de fundamento, não vejo como destinguir entre a propriedade tomada 
antes de um combate e a que é occupada ou destruida em uma operação militar.

E' digno de observação que os internacionalistas em geral são de opinião que ás revoltas deve ser applicado o Direito Internacional tanto quanto é possivel, mesmo que os revoltosos não tenham sido reconhecidos belligerantes. A belligerancia dos revoltosos é outra questão que é examinada pelos internacionalistas, e em geral estão todos de accordo em que, desde que os revolucionarios se estabelecem em um territoria e constituem um governo devem ser reconhecidos como belligerantes. Uma nota final porém é importantissima, e vem a ser que tudo quanto acaba derser dicto é no supposto de terem sido guardadas na guerra as leis consagradas pelo uso e pelos tratados. Assim como no Direito Interno, a violação de preceitos de policia torna o acto culposo, assim tambem os actos, mesmo sem o cunho de dolo, que foram practicados em contravenção das leis da guerra constituem em responsabilidade o Estado que desrespeitou os principios de Direito Internacional relativos aos meios de ataque e de defesa.

Caso diverso é o da responsabilidade do Estado por actos de revoltosos ou do povo amotinado ou da população que saqueia durante as revoltas ou as guerras. Os principios do Direito Interno, relativos á culpa são inteiramente applicaveis á hypothese. Si o Estado teve culpa por não ter usado da deligencia que o Direito exige para a insenção de responsabilidade pelos actos de outrem pagará o prejuizo. No caso contrario sua insenção de res. ponsabilidade pelo occorrido é innegavel. E' de repetir que, comquanto pareça, em vista do que é disposto no Direito Interno a este respeito, e quiçá para evitar a questão de facto, costumam alguns Estados consignar em tratados de immigração a sua não responsabilidade pelos actos de revoltosos ou do povo. Neste caso, deve dar-se a 
applicação das regras do Direito Interno que regulam o convencionado sobre taes materias.

Note-se que não é questão, em tal hypothese, de acto do Estado, de operação do poder constituido, de autoridade, e sim de violencia da massa popular que muito differe do Estado: ninguem é capaz de confundir Estado com povo, e menos ainda com uma multidão sublevada, assim como é difficil haver quem confunda nação com povo e com Estado.

Em conclusão pois fique bem assentado que a indemnização devida nos casos de desapropriação (de immoveis) e de requisição (de moveis e de immoveis) paga-se pela destruição da propriedade particular nos casos de guerra, e que a indemnização, quando não é estatuida, em taes circumstancias, pelas leis internas, é prescripta pelos principios do Direito Internacional, conforme a actual concepção da solidariedade dos cidadãos.

Miguel Cruchaga, que escreveu em 1899, mostra a evolução por que estava a passar, a esse tempo, o pensamento juridico, e aponta as opiniões de Fiore, Vattel, Calvo e outros, contrarios todos a pagar-se a destruição da propriedade particular pelas operações de guerra. Refere que a França sempre fez questão de deixar bem claro que, si pagava os prejuizos soffridos pelos particulares, o fazia unicamente a titulo de soccorro, e de nenhum modo por força de obrigação de indemnizar. O que parecia justo a Cruchava era distinguir actos propriamente de guerra, equiparados á força maior, os quaes não geram dever de indemnizar, salvo o caso de inutilidade da operação, e actos voluntarios e deliberados do belligerante, que determinam tal indemnização. Longe estava elle ainda da doutrina que veio a prevalecer após a grande guerra. De 1914 e 1919, promulgou a França diversas leis consagrando o principio da indemnização por quaesquer prejuizos provenientes de ope- 
rações militares. Do mesmo modo que no caso de accidentes no trabalho, não foi a indemnização assentada na culpa do Governo, mas "na egualdade e na solidariedade de todos os francezes nos encargos da guerra" Com effeito, assim como ha os riscos do negocio, assim como é repugnante á nossa conciencia que um operario e sua familia cáiam na miseria, por um accidente no trabalho, quando o patrão, sem culpa, é certo, está na opulencia, assim como se estabeleceu a solidariedade do patrão e do operario no trabalho, na lucta pela producção da riqueza, assim tambem é natural que se reconheça não ser justo salvar-se a patria á custa apenas de um ou de outro cidadão, que bem pode se indemnizado por todos os interessados na defeza do paiz, na repulsa aos ataques do solo sagrado da patria. E' este o fundamento da indemnização por actos em que a communhão nenhuma culpa tem.

Interessante é lembrar que Vattel dizia que uma indemnização desse genero resultaria em esgotamento do thesouro publico, tornando-se necessario um imposto para acudir a tão extraordinarias despezas. A mais admiravel porém é dizer Vattel ser isto impraticavel. De nenhum modo. Todos sabemos que os impostos por guerra são summamente communs. Até redentissima data tivemos nós brasileiros de pagar impostos pelas despezas da guerra do Paraguay. Justamente pois as premissas de Vattel levaram a França a tirar dellas uma conclusão diametralmente opposta: si para indemnização dos damnos nascidos da culpa ha necessidade de uma indemnização, si essa indemnização exige um imposto, concorrendo assim todos com uma pequena parte para a salvação commum, si essa indemnização esgota o thesouro publico, em vez de dizer, como disse Vattel que tal medida de um imposto especial para pagamento dos damnos é impracticavel, disse a França que é realizavel e que é o justissimo tributo devido por todos por ser nas. 
cido da solidariedade que deve ligar todos os membros da communhão social. E' a verdade proclamada pela lei francesa de 17 de Abril de 1919.

E' tempo de considerar um fossil a doutrina segundo a qual os actos do soberano não podem dar logar a uma responsabilidade nem gerar direito a uma indemnização; é tempo de deixar a doutrina do dominio eminente, segundo a qual o soberano era senhor de todos os bens de seus subditos, doutrina que é mesmo impotente para explicar a desapropriação, salvo si se estabelecer que não tem o particular direito á indemnização. E' tempo de se proclamar que todos os cidadãos de um paiz devem concorrer egualmente para a defesa da patria, com sua pessoa e gom seus bens: a destruição da propriedade de um em proveito de todos deve ser compensada por uma indemnização ao que viu seu bem sacrificado, embora sem culpa da parte da communhão. E' a unica doutrina acceitavel, é a unica que se deduz logicamente da obrigação de pagar o Governo tudo quanto requisita, é a unica compativel com o principio da indemnização de immoveis desapropriados e de moveis ou immoveis requisitados. Tanta razão ha para se indemnizar o particular pela perda do immovel que se desapropriou ou que se requisitou, antes do começo do combate para serviço de guerra, ou do movel que se requisitou antes do inicio das operações militares, como para se pagar o bem que se destruiu no curso de uma batalha, sem prévia requisição.

Coherencia só ha nesta doutrina. Os antigos, Fiore, Calvo, Vattel e outros eram de uma incoherencia que assombra. Causa admiração o seu illogismo.

Braz de Sousa Arruda. 